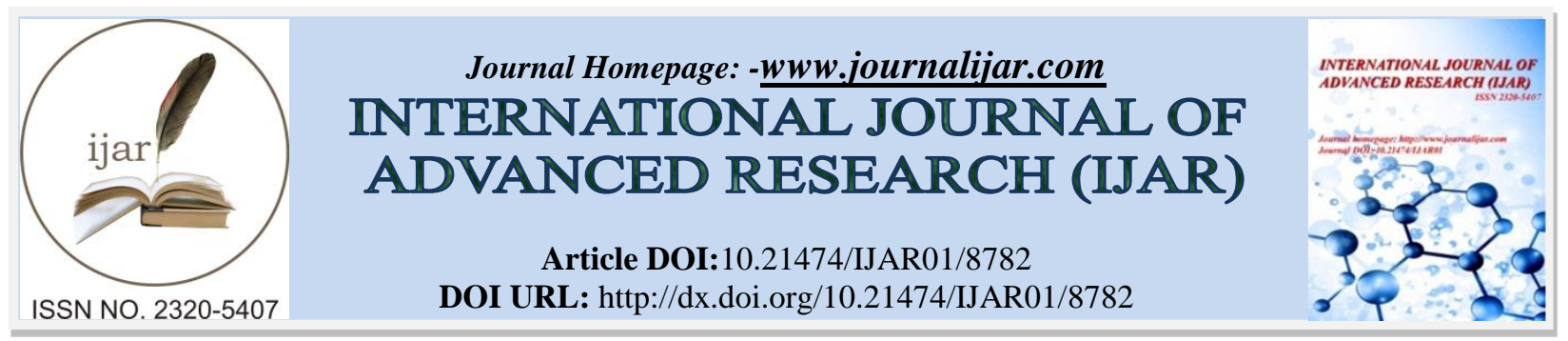

RESEARCH ARTICLE

\title{
ASSESSMENT OF DICKKOPF-1 AS A BIOMARKER OF HEPATOCELLULAR CARCINOMA IN EGYPTIANS.
}

Ola Atef Sharaki ${ }^{1}$, Ahmed El-Sayed Zeid ${ }^{2}$, Doreen Nazeih Younan ${ }^{1}$ and Mai Medhat El Boasaty ${ }^{3}$.

1. Department of Clinical and Chemical Pathology, Faculty of Medicine, Alexandria University.

2. Hepatobiliary Unit, Department of Internal Medicine, Faculty of Medicine, Alexandria University.

3. Department of Clinical and Chemical Pathology, Alexandria University Students' Hospital.

\section{Manuscript Info}

\section{Manuscript History}

Received: 02 February 2019

Final Accepted: 04 March 2019

Published: April 2019

Key words:-

Dickkopf-1, hepatocellular carcinoma, biomarker.

\begin{abstract}
Background: Hepatocellular carcinoma (HCC) is considered to be one of the most aggressive malignancies. Several studies have shown that dickkopf-1 (DKK1) is overexpressed in HCC tissue.

Objective and Methods: The present study aimed at demonstrating the diagnostic efficacy of serum levels of DKK1 in HCC in comparison to alpha fetoprotein (AFP). Eighty individuals were included in the present study, and categorized to three groups: Group I: 40 patients with HCC on top of viral liver cirrhosis, Group II: 20 patients with viral induced liver cirrhosis without HCC, and Group III: 20 healthy individuals. Serum levels of AFP and DKK1 were measured and compared in all groups.

Results: The values of AFP and DKK1 in group I were statistically higher than those in groups II and III. At the optimum value of 11.7 $\mathrm{ng} / \mathrm{ml}$, the sensitivity and specificity of serum AFP were $70.0 \%$ and $87.5 \%$, respectively. DKK1 had higher sensitivity (80.0\%) and specificity (90.0\%) than AFP, at the cut-off value of $1.28 \mathrm{ng} / \mathrm{ml}$ for the diagnosis of HCC. Area under the curve (AUC) was higher in DKK1 (0.811) than AFP (0.779) when discriminating between group I and other groups. It was noted that the combination of both markers had a higher sensitivity and specificity, and a larger AUC than each alone.

Conclusion: Serum DKK1 is a promising biomarker and is superior to AFP for HCC diagnosis. Combination of AFP and DKK1 improved the accuracy of $\mathrm{HCC}$ diagnosis in relation to each test alone.
\end{abstract}

Copy Right, IJAR, 2019,. All rights reserved.

\section{Introduction:-}

Hepatocellular carcinoma (HCC) represents about $70 \%$ to $85 \%$ of liver cancer, and is considered to be one of the most aggressive malignancies. According to Global Cancer Statistics (GLOBOCAN 2018) ${ }^{(1)}$, it is the $6^{\text {th }}$ most commonly diagnosed cancer and the $4^{\text {th }}$ leading cause of cancer-related deaths in 2018. It is considered the commonest tumor in 13 geographically diverse countries, including Egypt. ${ }^{(1)}$

Corresponding Author:-Mai Medhat EI Boasaty.

Address: - Department of Clinical and Chemical Pathology, Alexandria University Students' Hospital. 
Hepatocellular carcinoma is usually asymptomatic in early stages and most of patients present with non-operable disease, and this makes its early diagnosis critical for a good prognosis. So, continuous researches are ongoing to find an early sensitive and specific marker for HCC. ${ }^{(2)}$

Alpha fetoprotein is the best studied of all tumor markers and was considered the cornerstone for HCC diagnosis; however the American Association for the Study of Liver Diseases (AASLD) does not recommend its use anymore. ${ }^{(3)}$ Elevations of AFP levels might be encountered in patients having chronic viral hepatitis, who do not have HCC. ${ }^{(4)}$ Meanwhile, about one-third of early-stage HCC patients with small tumor mass have normal AFP levels. ${ }^{(5)}$

The need for a more sensitive and accurate tool for the detection of HCC had led to the emergence of various tumor biomarkers including; Dickkopf1 (DKK1). DKK1 is a secretory protein which is an antagonist of the Wnt/ $\beta$ catenin signalling pathway. ${ }^{(6,7)}$ It is rarely expressed in normal human adult tissues. ${ }^{(8,9)}$ DKK1 creates a negative feedback mechanism to regulate $\mathrm{Wnt} / \beta$ catenin signalling. ${ }^{(10)}$ However, this feedback mechanism is often abolished in cancers including HCC ${ }^{(11,12)}$ Several studies have shown that DKK1 is overexpressed in HCC tissue, but is not detectable in the corresponding non-cancerous liver tissue. ${ }^{(13,14)}$

Based on these previous studies, the present study hypothesized that serum DKK1 levels are increased in HCC patients because of DKK1 overexpression in the HCC tissue. In addition, the present study aimed at demonstrating the diagnostic efficacy of serum levels of DKK1 in various stages of HCC in comparison with AFP.

\section{Subjects and Methods:-}

Eighty individuals were included in the present study, and categorized to three groups:

1. Group I: 40 patients with HCC on top of HCV or HBV induced liver cirrhosis, who were further subdivided according to BCLC staging.

2. Group II: 20 patients with HCV or HBV induced liver cirrhosis without HCC, who were further subdivided according to Child Pugh classification.

3. Group III: 20 healthy individuals with matched age and sex as a control group.

All groups were subjected to history taking and clinical evaluation. Abdominal US was performed for all patients. Triphasic CT abdomen was done in case of focal hepatic lesion. Eight milliliters of whole blood were collected from all subjects, for complete blood count (CBC), prothrombin time, liver function tests (ALT, AST and albumin), kidney function tests (urea, creatinine), viral markers (HCV Ab, HBs Ag), AFP and DKK1 determination. DKK1 serum levels were measured using ELISA technique.

Data were fed to the computer and analyzed using IBM SPSS software package version 21.0. (Armonk, NY: IBM Corp). ${ }^{(15)}$

\section{Results:-}

The percentage of males and females was around $70 \%$ and $30 \%$ in the three groups. The age ranged between 36 and 74 years with a mean of about 55 years. Group I was almost equally distributed between single liver mass (52.5\%), and multiple liver masses (47.5\%); whether two to three masses $(5 \%)$ or more than three masses $(42.5 \%)$. According to BCLC classification, stage D was the commonest category (30\%), followed by stage C (27.5\%), stage B (22.5\%), and lastly stage A (20\%).

Regarding AFP and DKK1 levels, their mean values in group I were higher than those in groups II and III (647.23 $\mathrm{ng} / \mathrm{ml}$ and $4.07 \mathrm{ng} / \mathrm{ml}$ in group I, $31.75 \mathrm{ng} / \mathrm{ml}$ and $1.03 \mathrm{ng} / \mathrm{ml}$ in group II, $3.56 \mathrm{ng} / \mathrm{ml}$ and $0.77 \mathrm{ng} / \mathrm{ml}$ in group III, respectively). There was a statistically significant difference between group I in comparison to groups II and III, while there was no significant difference between groups II and III.

The diagnostic performance of serum AFP and DKK1 levels as markers for the diagnosis of HCC has been determined by plotting a receiver-operating characteristic (ROC) curve. At the cut-off value of $11.7 \mathrm{ng} / \mathrm{ml}$, the sensitivity of serum AFP in detecting HCC has been estimated to be $70.0 \%$, while its specificity has been shown to be $87.5 \%$. DKK1 has higher sensitivity (80.0\%) and specificity (90.0\%) than AFP, at the cut-off value of $1.28 \mathrm{ng} / \mathrm{ml}$ for the diagnosis of HCC (Table I). DKK1 has a higher AUC than AFP (0.843 and 0.809, respectively) (Figure I). 
It is noted from table I and figures $1 \& 2$ that the combination of both markers has a higher sensitivity and specificity, and a larger AUC than each alone.

Table I:-Diagnostic performance for AFP and DKK1 in discriminating HCC cases from other groups (cirrhosis + controls)

\begin{tabular}{|c|c|c|c|c|c|c|c|c|c|}
\hline & \multirow{2}{*}{$\underset{Z}{2}$} & \multirow[b]{2}{*}{$=$} & \multicolumn{2}{|c|}{ 95\% C.I } & \multirow{2}{*}{ 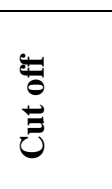 } & \multirow{2}{*}{ 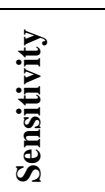 } & \multirow{2}{*}{ 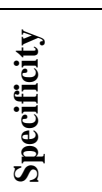 } & \multirow[b]{2}{*}{$\vec{a}$} & \multirow[b]{2}{*}{$\vec{z}$} \\
\hline & & & L.L & U.L & & & & & \\
\hline AFP & 0.809 & $<0.001^{*}$ & 0.715 & 0.904 & 11.70 & 70.0 & 87.5 & 84.8 & 74.5 \\
\hline DKK1 & 0.843 & $<0.001^{*}$ & 0.747 & 0.940 & 1.28 & 80.0 & 90.0 & 88.9 & 81.8 \\
\hline AFP \& DKK1 & 0.876 & $<0.001^{*}$ & 0.787 & 0.965 & & 82.50 & 95.0 & 93.55 & 85.55 \\
\hline
\end{tabular}

AUC: Area under the curve - $p$ value: probability value - CI: confidence interval - NPV: negative predictive value PPV: positive predictive value $-*$ :Statistically significant at $p \leq 0.05$

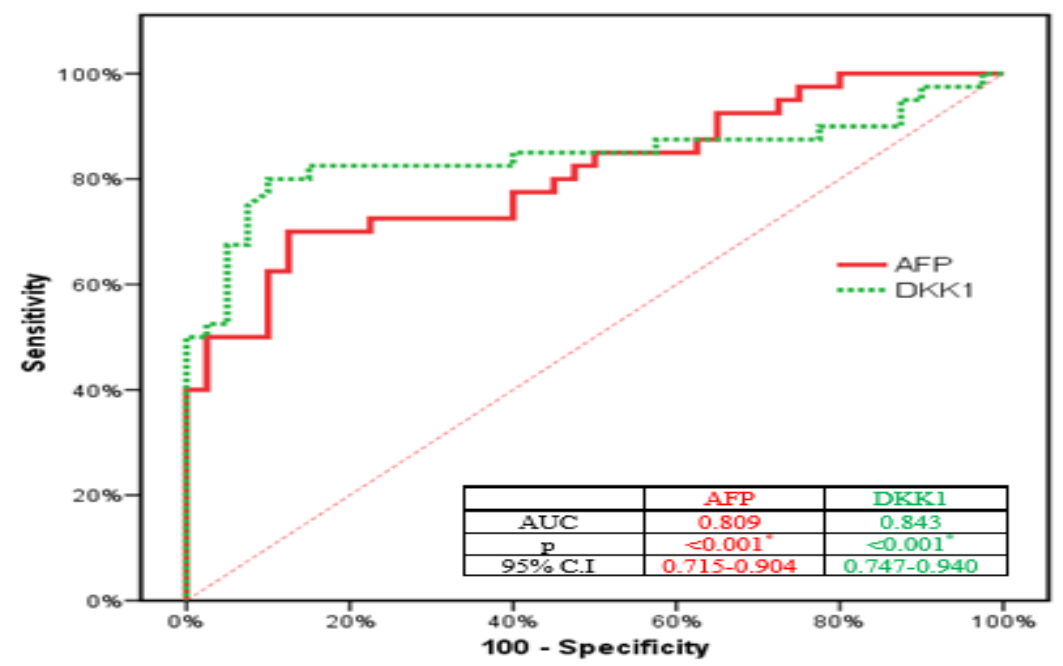

Figure 1:-Diagnostic performance of AFP and DKK1 in discriminating HCC cases from other groups (cirrhosis + controls)

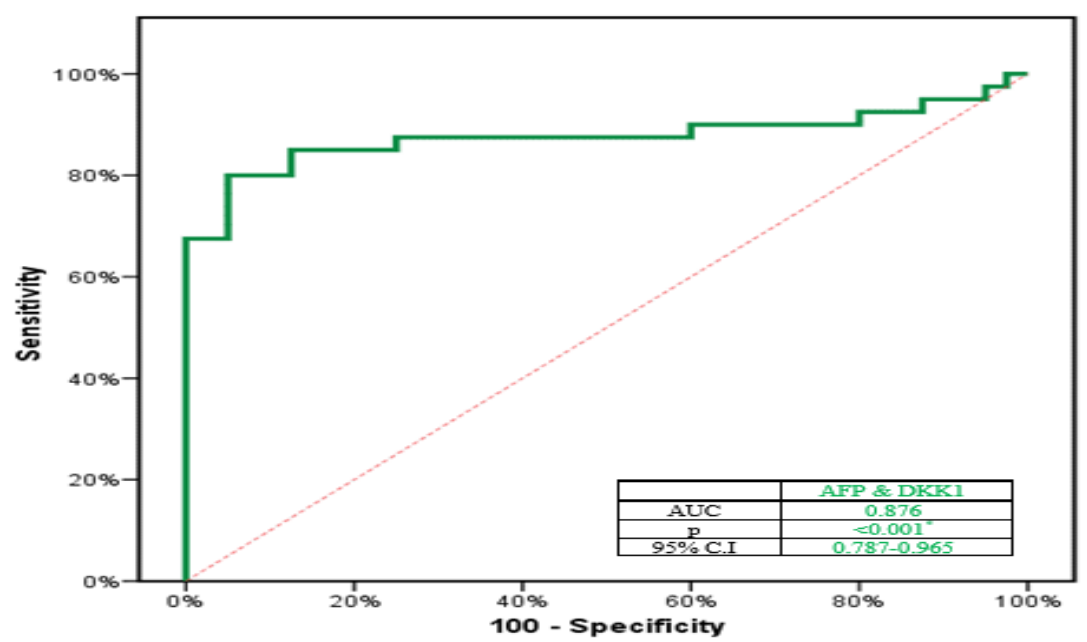

Figure 2:-Diagnostic performance of combination of AFP and DKK1 in discriminating HCC cases from other groups (cirrhosis + controls) 


\section{Discussion:-}

This study explored the diagnostic efficacy of DKK1 as a biomarker of HCC and was done on 40 HCC patients, 20 cirrhotic patients, and 20 healthy controls. In this study, serum DKK-1 level was significantly higher in HCC patients than those of cirrhotic and healthy groups, while there was no significant difference in DKK1 levels between cirrhotic and control groups. This was in accordance with what was stated by many authors ${ }^{(16-20)}$; as they found that DKK1 levels were significantly higher in HCC and could distinguish HCC patients from cirrhotic patients and from healthy controls.

In the present study, the optimum diagnostic cut-off value of DKK1 for the diagnosis of HCC was $1.28 \mathrm{ng} / \mathrm{ml}$. This agreed with almost all the studies, as seen in table II. On comparing the results of DKK1 and AFP for HCC diagnosis, DKK1 had a higher diagnostic performance than AFP. This was also in agreement with other studies reviewed, as seen in table II. Testing both DKK1 and AFP increased the diagnostic accuracy of HCC compared with either test alone. This combination proved to have a higher sensitivity and specificity, and a larger AUC, and this was in line with almost all of the studies reviewed (Table II).

On the other hand, Erdal et $\mathrm{al}^{(16)}$ stated that, even though AFP is superior to DKK1 in the diagnosis of HCC, the results of the combination were better than those of each marker alone. The exact reason for these different results is unclear. This discrepancy may be due to heterogeneity of carcinogenetic mechanisms because of various etiologies of chronic liver diseases, different ethnic groups and different number of cases studied.

Table II: Reviewed studies on the diagnosis of HCC, showing the optimum cut-off values for DKK1, diagnostic performance of AFP, DKK1 and their combination.

\begin{tabular}{|c|c|c|c|c|c|c|c|}
\hline $\begin{array}{l}\text { Study } \\
\text { (Year) }\end{array}$ & $\begin{array}{c}\text { DKK1 } \\
\text { optimum cut- } \\
\text { off value }\end{array}$ & Markers & AUC & $\begin{array}{c}\text { Sensitivity } \\
(\%)\end{array}$ & $\begin{array}{c}\text { Specificity } \\
(\%)\end{array}$ & $\begin{array}{l}\text { PPV } \\
(\%)\end{array}$ & $\begin{array}{l}\text { NPV } \\
(\%)\end{array}$ \\
\hline \multirow{3}{*}{$\begin{array}{l}\text { Our study } \\
\text { (2018) }\end{array}$} & \multirow[t]{3}{*}{1.28} & DKK1 & 0.843 & 80.0 & 90.0 & 88.9 & 81.8 \\
\hline & & AFP & 0.809 & 70.0 & 87.50 & 84.8 & 74.5 \\
\hline & & DKK1 + AFP & 0.876 & 82.5 & 95.0 & 93.6 & 85.6 \\
\hline \multirow{3}{*}{$\begin{array}{c}\text { Shen et al }^{(18)} \\
\quad(2012)\end{array}$} & \multirow[t]{3}{*}{2.15} & DKK1 & 0.848 & 69.1 & 90.6 & 89.3 & 70.6 \\
\hline & & AFP & 0.830 & 57.8 & 88.0 & 85.1 & 63.2 \\
\hline & & DKK1 + AFP & 0.889 & 73.3 & 93.4 & 98.4 & 86.6 \\
\hline \multirow{3}{*}{$\begin{array}{c}\text { Kim et al }^{(17)} \\
(2015)\end{array}$} & \multirow[t]{3}{*}{1.01} & DKK1 & 0.829 & 89.4 & 63.1 & 82.6 & 75.3 \\
\hline & & AFP & 0.794 & 65.0 & 89.5 & 89.8 & 64.3 \\
\hline & & DKK1 + AFP & 0.901 & 88.9 & 76.2 & 84.3 & 82.7 \\
\hline \multirow{3}{*}{$\begin{array}{c}\mathrm{Ge} \mathrm{et} \mathrm{al}^{(20)} \\
(2015)\end{array}$} & \multirow[t]{3}{*}{1.31} & DKK1 & 0.889 & 71.9 & 88.0 & 64.0 & 91.4 \\
\hline & & AFP & 0.831 & 79.7 & 89.4 & 68.9 & 93.7 \\
\hline & & DKK1 + AFP & 0.931 & 89.9 & 87.7 & 68.1 & 96.4 \\
\hline \multirow{3}{*}{$\begin{array}{c}\text { Erdal et al }^{(16)} \\
\quad(2016)\end{array}$} & \multirow[t]{3}{*}{1.40} & DKK1 & 0.726 & 72.5 & 61.5 & 65.9 & 68.6 \\
\hline & & AFP & 0.916 & 77.5 & 97.4 & 96.9 & 80.9 \\
\hline & & DKK1 + AFP & 0.946 & 75.0 & 92.3 & 92.1 & 87.8 \\
\hline
\end{tabular}

DKK1 level was elevated in most HCC patients even in those with non-conclusive AFP, and this agreed with Shen et $\mathrm{al}^{(18)}$, who concluded that DKK1 maintained diagnostic accuracy for HCC patients who were AFP negative. Similar to these results, Qin et $\mathrm{al}^{(21)}$ concluded that DKK1 can be detected in a subgroup of patients whose AFP levels are within the normal range.

This study had its points of strengths and limitations. Its main point of strength was the strict criteria for selecting patients in order to remove any confounding factors. The main limitation of the current study was the relatively small sample size.

\section{Conclusions:-}

Assessment of serum DKK1 levels could be a useful non-invasive biomarker for the diagnosis of HCC and proved to be superior to AFP. The combination of both serum AFP (cut off value of $11.7 \mathrm{ng} / \mathrm{ml}$ ) and serum DKK1 (cut off value of $1.28 \mathrm{ng} / \mathrm{ml}$ ) improved the diagnostic accuracy of HCC compared with either test alone. 


\section{Conflicts of Interest}

The authors declare no conflict of interest, whether personal or financial, regarding the publication of this paper.

\section{Funding Statement}

We did not receive any fund for conducting this study.

\section{Data Availability Statement}

All data are available upon request.

\section{References:-}

1. Bray F, Ferlay J, Soerjomataram I, Siegel RL, Torre LA, Jemal A. Global cancer statistics 2018: GLOBOCAN estimates of incidence and mortality worldwide for 36 cancers in 185 countries. CA: a cancer journal for clinicians. 2018.

2. El-Serag HB, Rudolph KL. Hepatocellular carcinoma: epidemiology and molecular carcinogenesis. Gastroenterology. 2007;132(7):2557-76.

3. Daher S, Massarwa M, Benson AA, Khoury T. Current and Future Treatment of Hepatocellular Carcinoma: An Updated Comprehensive Review. Journal of clinical and translational hepatology. 2018;6(1):69-78.

4. Ahn DG, Kim HJ, Kang H, Lee HW, Bae SH, Lee JH, et al. Feasibility of $\alpha$-fetoprotein as a diagnostic tool for hepatocellular carcinoma in Korea. The Korean Journal of Internal Medicine. 2016;31(1):46-53.

5. Tzartzeva K, Obi J, Rich NE, Parikh ND, Marrero JA, Yopp A, et al. Surveillance Imaging and Alpha Fetoprotein for Early Detection of Hepatocellular Carcinoma in Patients With Cirrhosis: A Meta-analysis. Gastroenterology. 2018;154(6):1706-18.e1.

6. Glinka A, Wu W, Delius H, Monaghan AP, Blumenstock C, Niehrs C. Dickkopf-1 is a member of a new family of secreted proteins and functions in head induction. Nature. 1998;391(6665):357-62.

7. MacDonald BT, Tamai K, He X. Wnt/beta-catenin signaling: components, mechanisms, and diseases. Developmental cell. 2009;17(1):9-26.

8. Fedi P, Bafico A, Nieto Soria A, Burgess WH, Miki T, Bottaro DP, et al. Isolation and biochemical characterization of the human Dkk-1 homologue, a novel inhibitor of mammalian Wnt signaling. The Journal of biological chemistry. 1999;274(27):19465-72.

9. Krupnik VE, Sharp JD, Jiang C, Robison K, Chickering TW, Amaravadi L, et al. Functional and structural diversity of the human Dickkopf gene family. Gene. 1999;238(2):301-13.

10. Gonzalez-Sancho JM, Aguilera O, Garcia JM, Pendas-Franco N, Pena C, Cal S, et al. The Wnt antagonist DICKKOPF-1 gene is a downstream target of beta-catenin/TCF and is downregulated in human colon cancer. Oncogene. 2005;24(6):1098-103.

11. Pendas-Franco N, Garcia JM, Pena C, Valle N, Palmer HG, Heinaniemi M, et al. DICKKOPF-4 is induced by $\mathrm{TCF} /$ beta-catenin and upregulated in human colon cancer, promotes tumour cell invasion and angiogenesis and is repressed by 1alpha,25-dihydroxyvitamin D3. Oncogene. 2008;27(32):4467-77.

12. Yu B, Yang X, Xu Y, Yao G, Shu H, Lin B, et al. Elevated expression of DKK1 is associated with cytoplasmic/nuclear beta-catenin accumulation and poor prognosis in hepatocellular carcinomas. Journal of hepatology. 2009;50(5):948-57.

13. Prieto PA, Cha $\mathrm{CH}$. DKK1 as a serum biomarker for hepatocellular carcinoma. Hepatobiliary Surgery and Nutrition. 2013;2(3):127-8.

14. Watany M, Badawi R, Elkhalawany W, Abd-Elsalam S. Study of Dickkopf-1 (DKK-1) Gene Expression in Hepatocellular Carcinoma Patients. Journal of Clinical and Diagnostic Research : JCDR. 2017;11(2):OC32-OC4.

15. Kirkpatrick LA FBAsgtISsfvSeB, Calif.: Wadsworth, Cengage Learning; 2015.

16. Erdal H, Gul Utku O, Karatay E, Celik B, Elbeg S, Dogan I. Combination of DKK1 and AFP improves diagnostic accuracy of hepatocellular carcinoma compared with either marker alone. The Turkish journal of gastroenterology : the official journal of Turkish Society of Gastroenterology. 2016;27(4):375-81.

17. Kim SU, Park JH, Kim HS, Lee JM, Lee HG, Kim H, et al. Serum Dickkopf-1 as a Biomarker for the Diagnosis of Hepatocellular Carcinoma. Yonsei medical journal. 2015;56(5):1296-306.

18. Shen Q, Fan J, Yang XR, Tan Y, Zhao W, Xu Y, et al. Serum DKK1 as a protein biomarker for the diagnosis of hepatocellular carcinoma: a large-scale, multicentre study. The Lancet Oncology. 2012;13(8):817-26.

19. Fouad YM, Mohamed HI, Kamal EM, Rasek MA. Clinical significance and diagnostic value of serum dickkopf-1 in patients with hepatocellular carcinoma. Scandinavian journal of gastroenterology. 2016;51(9):1133-7.

20. Ge T, Shen Q, Wang N, Zhang Y, Ge Z, Chu W, et al. Diagnostic values of alpha-fetoprotein, dickkopf-1, and osteopontin for hepatocellular carcinoma. Medical oncology (Northwood, London, England). 2015;32(3):59.

21. Qin QF, Weng J, Xu GX, Chen CM, Jia CK. Combination of serum tumor markers dickkopf-1, DCP and AFP for the diagnosis of primary hepatocellular carcinoma. Asian Pacific journal of tropical medicine. 2017;10(4):409-13. 